\title{
ENGINEERING METHODS PACK - CARDS TO IMPROVE ENGINEERING RESEARCH
}

\author{
Danielle HENDRIKS ${ }^{1}$, Koen VAN TURNHOUT ${ }^{2}$, Lejo BUNING ${ }^{1}$, Ethel ten ELZEN ${ }^{1}$, \\ Andries VAN STRALEN ${ }^{1}$, Tanja TANKINK ${ }^{1}$ and Ellen WESSELINGH ${ }^{1}$ \\ ${ }^{1}$ HAN University of Applied Sciences, Ruitenberglaan 26, 6802 CE, Arnhem, The \\ Netherlands \\ ${ }^{2}$ Utrecht University of Applied Sciences, Heidelberglaan 15, 3584 CS, Utrecht, The \\ Netherlands
}

\begin{abstract}
Students and young professionals in engineering need to know several research methodologies to reach high quality results. This is particularly important when engineers from multiple engineering disciplines work together. However, it is not self-evident for students to use tools to determine which research methods are meaningful. This paper addresses the development of a tool to help students at HAN University of Applied Science engineering bachelor programmes in doing research from the start of their studies. The tool consists of a card set called Engineering Methods Pack, consisting of 43 cards, each explaining a research method. The use of research methods can help to increase the (innovative) quality of the professional products of engineering. The method cards are instrumental in broadening the range of research methods used. Project groups choose the most relevant and efficient methods and visually plan research activities. This paper reports on the design and implementation of this card set in engineering programmes. The card set was received with mixed feelings by teachers and enthusiastically by students. Teachers doubt the added value of a cross-disciplinary set. Students valued the practical use, having lively discussions and exploring different methods with a focus on how to combine methods. The development team is positive about the set, but proper introduction and guidance is needed both for students and lecturers working with the Engineering Methods Pack.
\end{abstract}

Keywords: Engineering education, research methods, DOT-framework

\section{INTRODUCTION}

The Dutch Professional Higher Education system (Universities of Applied Sciences, UAS) emphasizes 21st Century skills needed to become a 'future proof engineer' [1]. The engineering study programmes have adapted to this new paradigm by creating new curricula in the past decade. The national framework for engineering defines eight competences [4]. These competences include a critical thinking approach in the creation of products with practical functionality and relevance, working with efficiency, methodical thoroughness, method mix, ethical approach and traceability. A central concern in these new curricula has been to increase students' inquisitiveness and to nurture their research ability. Educational guidelines for this aspect of higher education, such as [2][3], are often rooted in social science and in our experience engineering practice differs significantly from this heritage. Three barriers for acquiring research ability in engineering were identified. First, students often use a design method (such as the Delft Method or V-model) as a starting point instead of a research method or tool. The focus on design method diverts attention from using proper research methodologies, sometimes leading to sub-optimal quality of results. Second, in multi-disciplinary projects students miss out on opportunities to learn research methods, because of cultural and linguistic challenges that arise from the use of different design methodologies. Finally, in interdisciplinary projects the use of different design methods leads to confusion over differences in terminology used in different disciplines.

In 2018 educators at HAN University of Applied Science (HAN UAS) identified a need to create a shared language on research methods, enabling cooperation amongst students from different disciplines. To provide an accessible format, a card set was chosen. This approach is common in design-oriented disciplines, [5][6] and in the communication design and information and communication technology programmes, such sets were already in use and shown to be effective [7][8]. The advantage of a card set 
is that it is user friendly for searching, selecting and combining research methods. At the same time the available text space is limited, so such a set needs to be used in conjunction with more extensive sources. The format is new to most technical engineering programmes so it might be a little bit uneasy for lecturers.

To develop the card set a team was formed with representatives from the engineering programmes at HAN UAS. These programmes are bachelor Automotive, Electrical Engineering, Industrial Design Engineering, Industrial Engineering \& Management, Mechanical Engineering, and the Master of Engineering Systems. The team was deliberately formed with representatives from all engineering programmes to find a common ground among the disciplines, and to create broad understanding and acceptance of this new way of working. The team did research on the methods used in practice, in sessions with lecturers, researchers and professionals from different disciplines in engineering. It was found that the study programmes together use a lot of different research methods and tools, more than the 55 available cards. The team discussed which methods to select and - where necessary - rephrased methods or wrote new method cards. After multiple rounds of discussion to decide on which methods and tools to pick for the set, the set was finalized in June 2019. Emerging remarks during the implementation of this new way of working in existing curricula were contractionary; enthusiasm and open attitude alternated with the perception of 'yet another method, we use so many already', and doubts on the applicability and placement in the curriculum.

This paper consists of three parts. The first part describes in more detail the purpose of the Engineering Methods Pack. The second part explains some tools to support the application of the set, such as the planning poster. Finally, experiences with using this set-in educational engineering projects are shared, and conclusions and recommendations given.

\section{PURPOSE AND LAYOUT}

\subsection{Purpose of the card set}

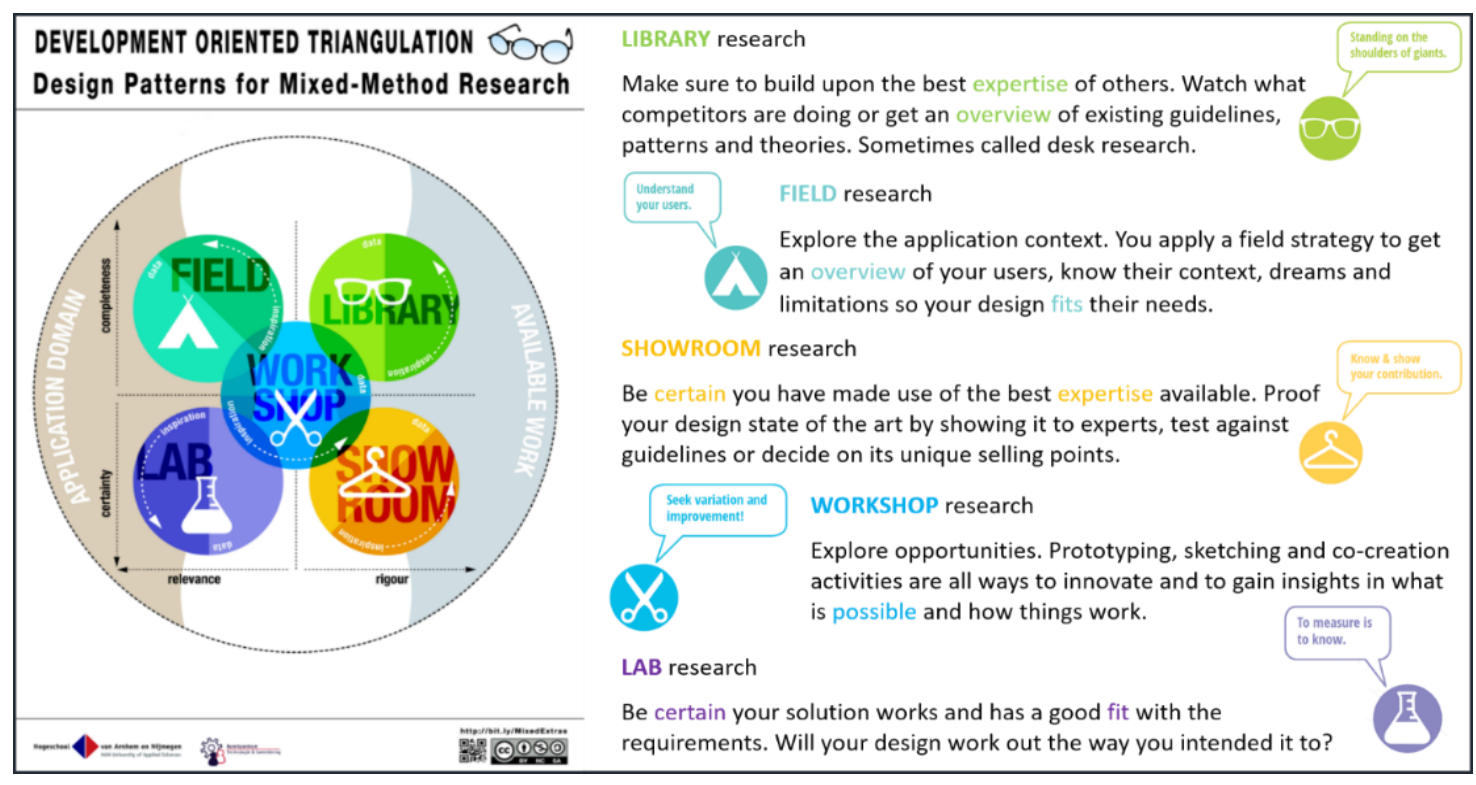

Figure 1. Research strategy domains and their purpose

The purpose of the Engineering Methods Pack is to enhance the quality of practice-oriented research projects. The method builds on the Development Oriented Triangulation (DOT) framework [9]. This framework allows for categorization of methods, supporting the understanding of similarities between research methods and allowing to pick different research strategies that support the overall quality of the work. In the DOT framework, five research strategy domains have been identified, which are elaborated above in Figure 1 [7][11]. The framework is depicted on a poster that shows each research strategy domain in the entire research project and the relations between the domains.

For each research strategy, several research methods have been selected, resulting in a total of 43 research methods. Methods include typical engineering research activities like prototyping, designing, modelling and simulations. The physical format of playing cards stimulates mixing of various methods, 
thus balancing trade-offs to be made in development-oriented research and fostering reliability and validity of results. The variety of methods available to choose from nurtures an open-minded research attitude, [8] overuse of well-known method prescriptions. Using these methods increases the potential quality of the work and supports justification of choices during the process of collecting knowledge and applying it to realize tangible products [3][10].

To support the use of other methods that are not in the Engineering Methods Pack, a joker card is provided, which can be freely used. To provide tangible products that can be used to show and discuss research results with stakeholders, a set of so-called stepping-stones has been selected.

\subsection{Layout of the cards}

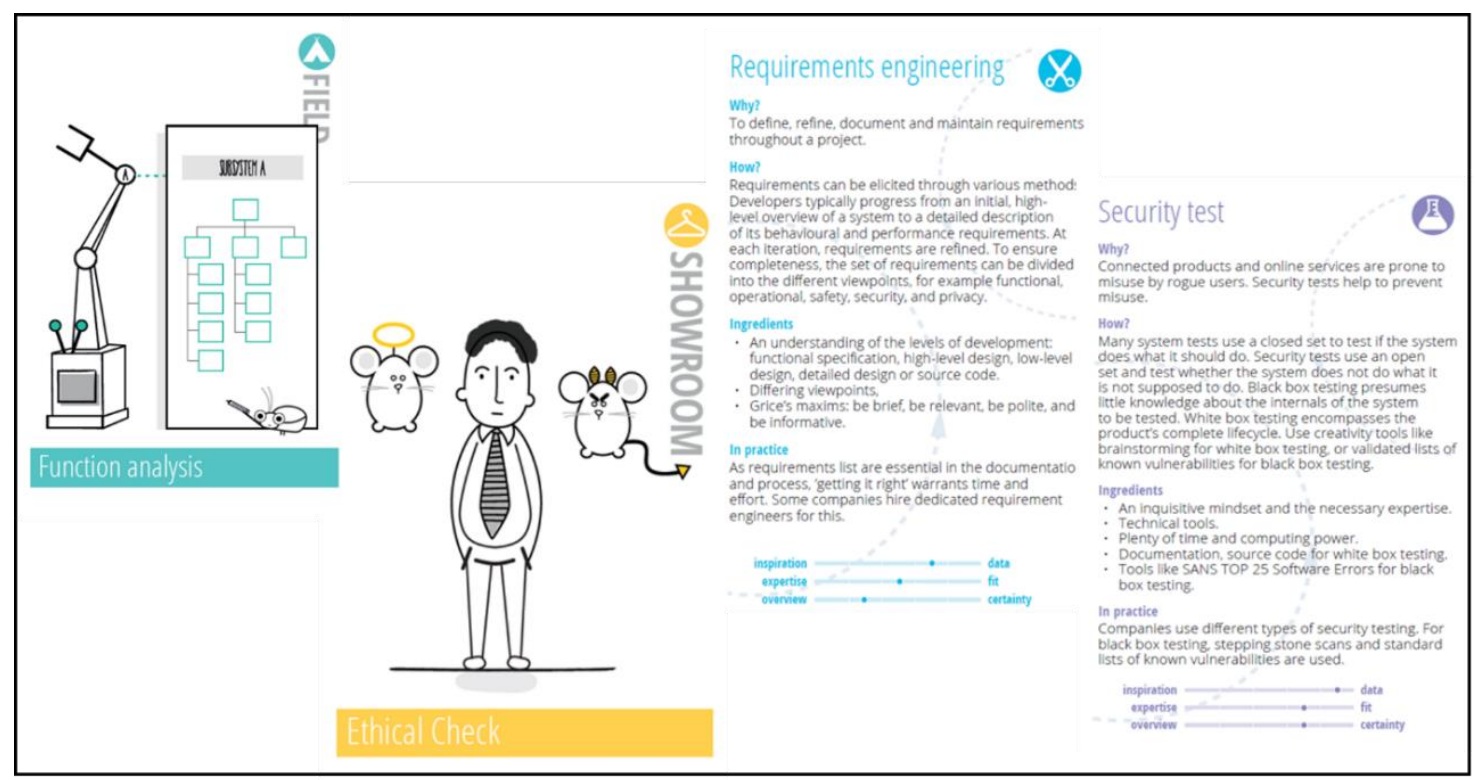

Figure 2. Card front side and back side examples [13]

The layout of the cards is presented in Figure 2. The back side of each card briefly describes why the method should be used, how it is used, what the necessary ingredients are and an example from use in practice. This should enable the engineers to decide whether the method is useful for their specific project.

\section{APPLICATION TOOLS FOR USE IN EDUCATION PROJECTS}

The Engineering Methods Pack can be used with various supporting tools. This section describes the following options: i) planning poster, ii) card sorting and iii) reverse engineering.

\subsection{Planning poster}

The first tool is a planning poster, an example of which is shown in Figure 3. The planning poster provides a visual tool to structure a complex problem. Team members can work together by choosing the most relevant and efficient methods to solve questions, and visually plan their research activities. The poster shows four different phases. The upper half can be used to write down what must be known or understood. The bottom half of the poster provides space to sort the relevant method cards for each phase, in an interactive discussion within the team. After the team has agreed that this is a complete set of questions and corresponding research methods, a picture can be taken for future reference.

Using the poster requires the following steps: outlining the tangible professional products to meet the project objective, formulating the main research questions that have to be asked in every phase, selecting the appropriate research methods and placing the cards in the right phase, adding stepping stones. When all these steps are done, the questions, research methods and stepping-stones must relate to a justification of the combination. Sometimes, further on in the research project, this phase must be revisited, and changes or refinements must be made. 


\subsection{Card sorting}

The choice of research methods with the use of the planning poster can itself be triangulated by using the card sorting method. With this method, the students are asked to visualise their project in their mind. They then take the entire card pack and sort the cards one by one on two stacks: discard and keep. They have five minutes to perform this task. After five minutes, the keep stack is taken, and the same process is repeated. In two rounds, students can reduce the number of methods to be used from more than 40 to around 10. Comparing the choice from the card sorting method with the choice from the planning poster method can reveal further justification to apply or to leave out research methods.

\subsection{Reverse engineering}

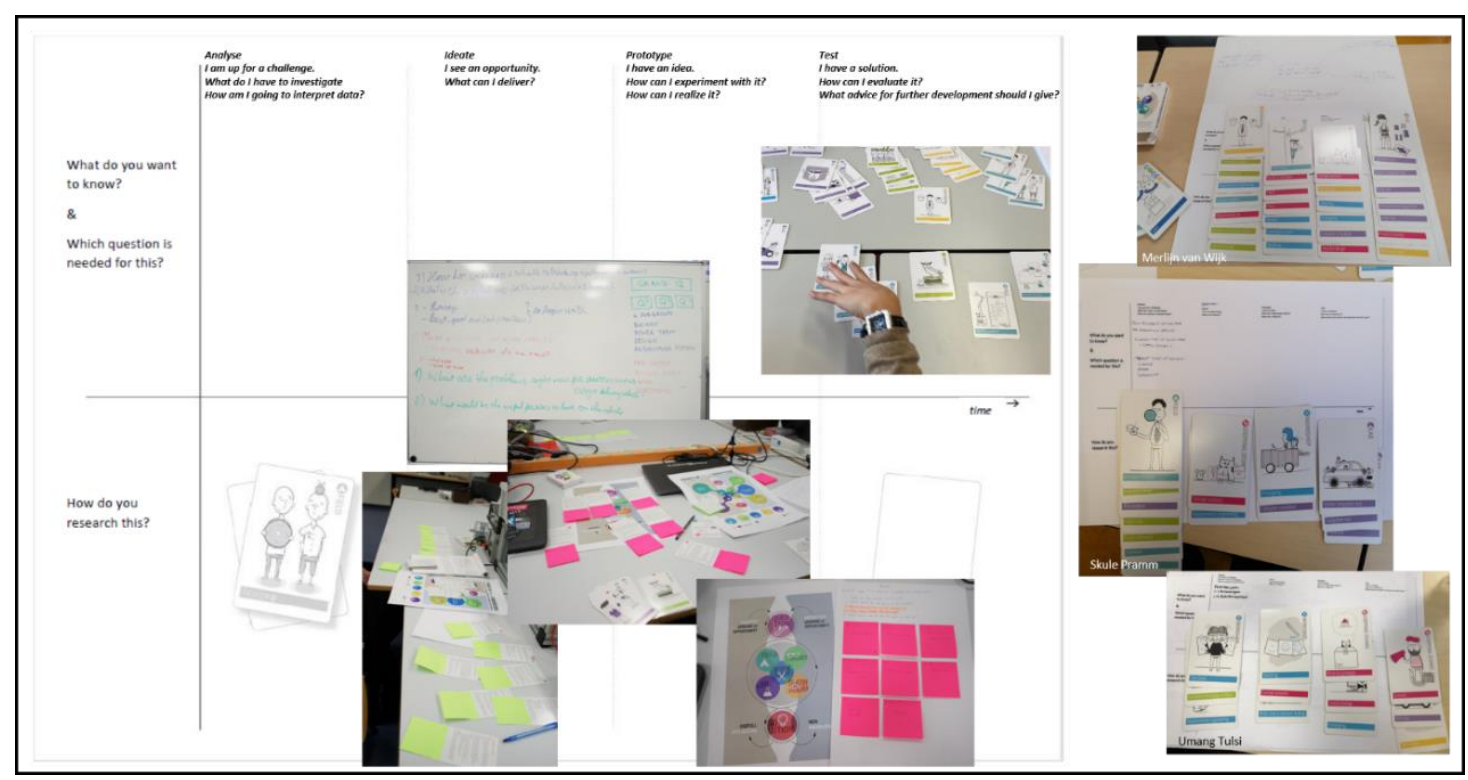

Figure 3. Planning poster and examples of use of the card set, by students from Automotive, and Industrial Design Engineering respectively

When not using the cards for the execution of a concrete research project, the reverse engineering method may be used to introduce the method cards. This tool is used with an existing research article or report. Students read the article or report, and then use the method cards to determine which research methods were used for the research presented in the article or report. The tool is thus allowing students to learn from previous work and get acquainted to using the Engineering Methods Pack at the same time. If time permits, poor research and excellent research articles or reports may be used, so students get to analyse what makes the difference between poor and excellent research.

\section{FROM THEORY TO PRACTICE}

The Engineering Methods Pack has been available since June 2019. Up to now, it has been used in four study programmes. The experiences and results for each study programme are presented in the next paragraphs. Pictures of cards used by students are given in Figure 3.

\subsection{Bachelor programme Automotive}

In the Automotive study programme, students encounter their first real life project including the use of research ability in the second year of study. The set was introduced to the entire bachelor lecturer team in September 2019. Since the Automotive team is quite a big team, not the entire team was present. Further introduction was given to part of the team responsible for the second year of the programme, in the hopes that the coaches for the project would adopt the Engineering Methods Pack. It was also introduced in the part of the team responsible for teaching topics that are considered non-technical. Not all lecturers were enthusiastic about the approach. Less enthusiastic lecturers argued there was no added value to the research methods from the books already in use, no need to change the way teaching had been done in the previous decade, or that other skills are more urgent.

The experience with students shows, that - given proper instruction and guidance - students easily accept the use of the Engineering Methods Pack and see the value of using it as a tool to enhance quality 
of their work. This is especially observed when students use the card set in their project, instead of during a theoretical lecture. The set is more convincing when students and lecturers work with it in a real project. Observation suggests that students enjoy working with the set. The cards ignite lively discussions in the project groups. The planning poster is the tool that is mainly used.

It is too early to conclude whether the use of the methods leads to better quality of the project deliverables and development of research ability. However, the enthusiasm of the students on the research perspective in projects is an improvement to the previous situation. An experiment with the use of other methods packs showed that further guidance of students is needed to assure they apply the methods right and evaluate or justify their use [8]. This complies with the finding that unsupervised learning of research ability is ineffective [8].

\subsection{Bachelor programme Industrial Design Engineering}

In the Industrial Design Engineering (IDE) programme third year project, students from various engineering programmes work on a multidisciplinary assignment. Under the guidance of a lecturer, the questions of the IDE students were roughly formulated. The questions focused mainly on the analysis phase. For these questions, students went through the cards to find out which methods fit well with the analysis phase. The main observation was that students took several cards and discussed about making combinations. They also discussed how they could help each other. The cross-pollination between the students is likely to improve the reliability of their deliverables and development of their research ability. Afterwards, the lecturer indicated that the cards were very useful because the students themselves chose methods that were not obvious at first sight. However, use of the cards showed that some typical methods for Industrial Design Engineering projects are not included in the set. A solution for this situation is provided by the joker card. It should be mentioned that IDE lecturers are familiar with using cards from other situations.

\subsection{Bachelor programme Industrial Engineering \& Management}

Students Industrial Engineering \& Management have affinity with research methods like interviews and observation. Left to their own devices, they mostly chose research methods in that direction. When students define their research questions, and start thinking about how to answer those questions, the cards help them to broaden their perspectives. The different methods can be used to ask themselves questions like 'what information would this method bring me, how would that help me?' When properly guided, students understand the logic of the set-up, and come to a more complete set of research methods, with a better coverage of the research strategy domains, than they do using standard literature used in the programme.

\subsection{Programme Master of Engineering Systems}

In the master programme, the method cards have been used intermittently, without proper follow-up in the assessment phase. However, the acceptance and ease of use can be observed when proper instruction and guidance are provided. This is like the observations in the bachelor programmes.

\section{CONCLUSIONS AND RECOMMENDATIONS}

\subsection{Conclusions}

The Development Oriented Triangulation framework is an established framework and has been in use with various study programmes to date. Because an existing framework was used, the developers could concentrate on building a hands-on tool to implement the framework for engineering studies. This paper describes that development and implementation, enabling students to:

- Become enthusiastic about developing and applying research ability.

- Be inspired to use all kinds of research methods.

- Develop a common language in relation to research ability.

- Gain experience in working with research methods in the contexts of engineering projects.

- Understand the value of combining different research strategies.

Some of these benefits have been reported for other domains, [7][8] but it was an open question to what extent they would hold up in engineering studies. The experience up to now shows that students are indeed inspired to use more than the obvious methods and accept the added value of combining different research strategies. They are also enthusiastic about doing research. 
In the development phase of the Engineering Methods Pack, it was found that the different study programmes use many different research methods and tools. Choices had to be made due to the physical limits of a card set, meaning not all research methods relevant for engineering practice are included in the final set. Because of the variety in methods used in the various professional fields in engineering, the joker card was used often in implementation.

In the implementation phase, various levels of enthusiasm among colleagues were observed. The participating students, after an introduction and with proper guidance, enthusiastically used the method cards. Especially when the card set is used in the context of their actual project. It is assumed that unfamiliarity with the use of the set, and the underlying model, causes lecturers to be less enthusiastic. More workshops for colleagues should be organised, allowing them to practice with this new way of working in a safe environment before applying in the curriculum. In these workshops, the theory on research ability (reliability, validity, research attitude) can also be discussed. The idea that the methods cards enable multidisciplinary work with the use of existing research methods can be emphasised, and the sources of the methods mentioned in the cards can be discussed.

\subsection{Recommendations}

This research shows that it would be useful to do systematic research on the application of the method in practice, and to measure whether the method actually contributes to the quality of the work done by students of the engineering programmes. Results could be further enhanced by measuring compliance with the professional practice.

The frequent use of the joker card can be understood, because the set was designed to serve a very broad audience. This indicates the usefulness of a few blank cards allowing students to write down a method of their own choice.

To overcome lecturer reservations, it is recommended that lecturers start working with the set in the projects, so they can observe students enthusiastically working with the set.

\section{REFERENCES}

[1] Trilling B., Fadel C. (2009), $21^{\text {st }}$ Century Skills - learning for life in our times, Partnership for $21^{\text {st }}$ Century Skills, Jossey-Bass a Wiley Imprint

[2] Berg, N. van der (2016). Grenspraktijken. Opleiders en onderzoekers in ontwikkeling. Public lecture. Stoas Wageningen | Vilentium Hogeschool.

[3] Losse, M. (2018). Onderzoekend vermogen ontwikkelen bij studenten. Een methodiek voor hbodocenten. (Boom: Amsterdam)

[4] HBO Engineering (2016). Dutch Bachelor's degrees in Engineering - A competence-based Bachelor profile.

[5] Lucero, A., Dalsgaard, P., Halskov, K., \& Buur, J. (2016). Designing with cards. In Collaboration in creative design (pp. 75-95). Springer, Cham.

[6] Gray, C. M., Seifert, C. M., Yilmaz, S., Daly, S. R., \& Gonzalez, R. (2016). What is the content of "design thinking"? Design heuristics as conceptual repertoire. International Journal of Engineering Education, 32.

[7] Turnhout, K. van, Coppens, A., Craenmehr, S. Bakker, R. (2016). Triangulation First: Teaching Research in a Multidisciplinary Design and Engineering Environment. Proceedings of the International Conference on Engineering and Product Design Education. Aalborg, Denmark.

[8] Turnhout, K. van, Köppe, C., Schuszler, P., Tankink T., Bakker, R. (2018). Research Education Nurtures Inquisitiveness of Professional Design and Engineering Students. E\&PDE, 018. London, United Kingdom.

[9] Turnhout, K. van, Bennis, A., Craenmehr, S., Holwerda, R., Jacobs, M,., Niels, r., Zaad, L., Hoppenbrouwers, S., Lenior, D. Bakker, R. Design patterns for mixed-method research in HCI. In Proceedings of the 8th Nordic Conference on Human-Computer Interaction: Fun, Fast, Foundational, pp. 361-370. 2014.

[10] Expertgroep Protocol. (2014). Beoordelen is mensenwerk. Report. Den Haag: Vereniging Hogescholen.

[11] Hendriks, D., Brouwer, P., Buning, L., Elzen, E. ten, Kaandorp, R., Stralen, A. van, Tankink, T., Wesselingh, E., Henneke, L., Turnhout, K. van (2019). Engineering Methods Pack. Card set. HAN University of Applied Sciences, Arnhem. ISBN/EAN: 9990002072178. Available from: http://bit.ly/2koUICE 